\title{
Fabrication and Characterization of Submicron Scale Spherical RDX, HMX, and CL-20 without Soft Agglomeration
}

\author{
Xinlei Jia $\left(\mathbb{D},{ }^{1}\right.$ Lixin Wei $\left(\mathbb{D},{ }^{2}\right.$ Xuewen Liu, ${ }^{1}$ Chao Li, ${ }^{1}$ Xiaoheng Geng, ${ }^{1}$ Mingming Fu, ${ }^{1}$ \\ Jingyu Wang $\mathbb{D}^{3}{ }^{3}$ Conghua $\mathrm{Hou}\left(\mathbb{D},{ }^{3}\right.$ and Jing $\mathrm{Xu}^{4}$ \\ ${ }^{1}$ College of Chemical Engineering and Safety, Binzhou University, Binzhou, Shandong 256600, China \\ ${ }^{2}$ School of Petroleum Engineering, Changzhou University, Changzhou, Jiangsu 213016, China \\ ${ }^{3}$ School of Environment and Safety Engineering, Shanxi Engineering Technology Research Center for Ultrafine Powder, \\ North University of China, Taiyuan, Shanxi 030051, China \\ ${ }^{4}$ Administrative Examination and Approval Authority, Binzhou, Shandong 256600, China
}

Correspondence should be addressed to Lixin Wei; weilixin73@163.com and Jingyu Wang; wjywjy67@163.com

Received 2 August 2019; Revised 6 October 2019; Accepted 4 November 2019; Published 26 November 2019

Academic Editor: Michael Harris

Copyright ( 2019 Xinlei Jia et al. This is an open access article distributed under the Creative Commons Attribution License, which permits unrestricted use, distribution, and reproduction in any medium, provided the original work is properly cited.

In this study, a novel spray drying-assisted self-assembly (SDAS) technology was proposed to prepare submicron elemental explosives with good morphology, uniform dispersion, and low sensitivity and spherical submicron RDX, HMX, and CL-20 particles without soft agglomeration were fabricated via such a method. Structural characterizations and thermal stability of the composites were systematically studied by scanning electron microscopy (SEM), X-ray diffraction (XRD), and differential scanning calorimeter (DSC). Moreover, safety performance was analyzed by qualitative testing of impact sensitivity and friction sensitivity. The XRD analysis demonstrated that HMX and CL-20 refined by SDAS maintained the crystal structure of $\beta$-HMX and $\varepsilon$-CL-20 before and after refinement, whereas the HMX crystal structure after spray recrystallization refinement was transformed from $\beta$-HMX to $\alpha$-HMX. The DSC results indicated that the thermal decomposition peak temperature of the three particles refined by the SDAS technology had a minimum advancement, and the thermal stability of the particles was relatively superior. More importantly, the $H_{50}$ of the RDX, HMX, and CL-20 refined by this novel method was increased to $48.3 \mathrm{~cm}$, $44.6 \mathrm{~cm}$, and $31.1 \mathrm{~cm}$, and the probability of friction explosion was decreased to $62 \%$, $62 \%$, and $80 \%$, respectively, thus significantly improving the safety performance as compared with the sample refined by spray recrystallization.

\section{Introduction}

Hexanitrohexaazaisowurtzitane (CL-20, HNIW), cyclotetramethylenetetranitramine (HMX), and cyclotrimethylenetrinitramine (RDX) are three most typical nitramine explosives. And they are widely used as the energy source for explosive devices due to their stable performance and high-energy density [1]. However, with the continuous development of technology and weapon systems, ammunition is required to ensure high precision, fierce power, and long range while maintaining high safety in a variety of environments. Therefore, the high-energy and insensitive development of ammunition is an effective way to meet the needs of weapon systems [2]. Conventional nitramine explosives, having large crystal defects such as angular or void morphology and existing more impurities, cannot satisfy the requirements of weapon system development. And ultrafine treatment of explosives is one of the ways to achieve this indicator. It can reduce the probability of hot spot generation and propagation by making the morphology of the explosive particles spheroidized and the particle size become smaller, thereby achieving the purpose of desensitization. The surface molecular arrangement and crystal structure of the ultrafine explosives have changed, giving rise to peculiar surface effect, small size effect, quantum effect, and macroscopic quantum tunneling effect which are not possessed by irregularly shaped explosives, so that the ultrafine explosives have a series of excellent physical, chemical, surface, and interface properties and can achieve extraordinary effects when used $[3,4]$. 


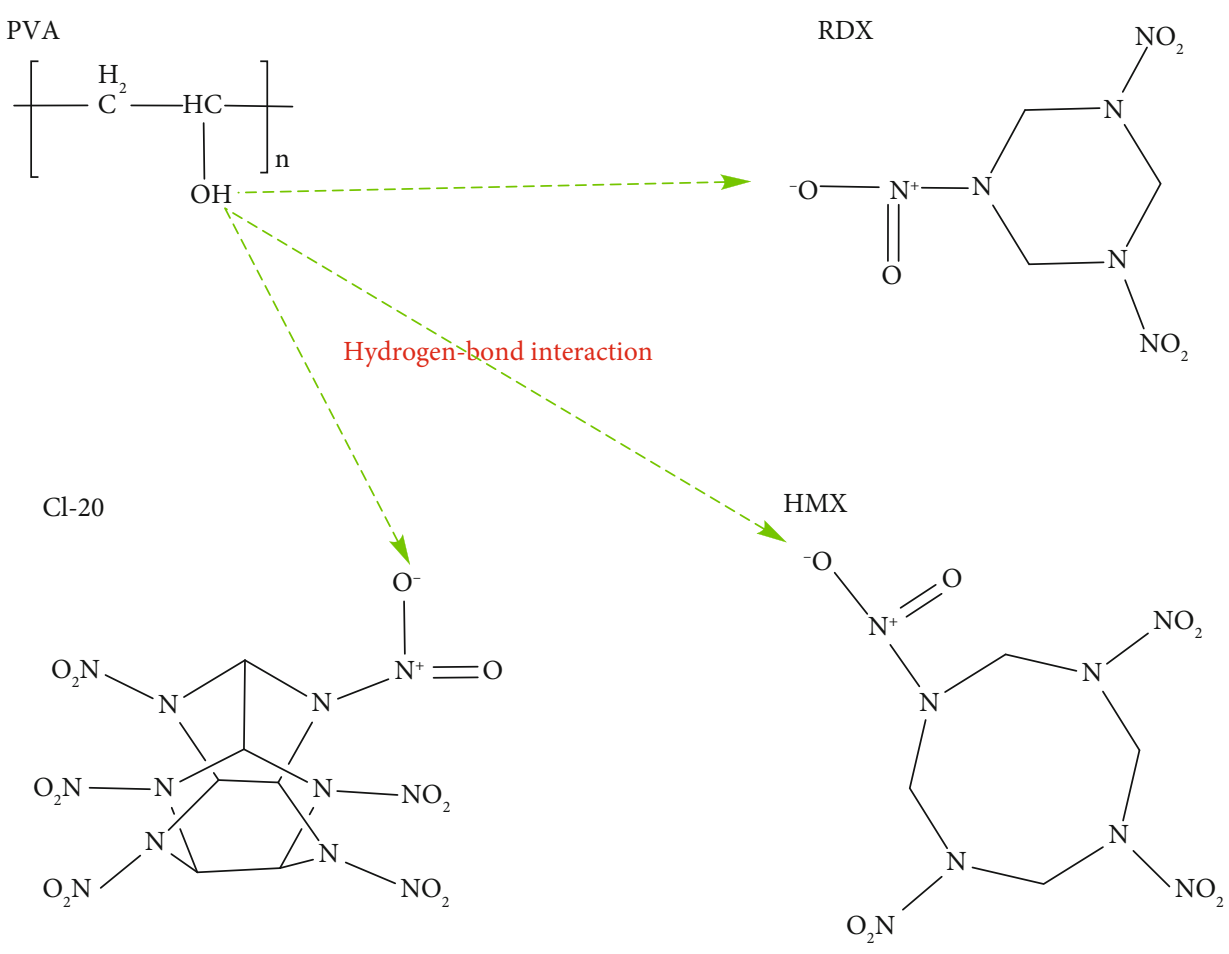

Figure 1: Schematic diagram of hydrogen bond between PVA and explosive molecules.

Reports on the refinement and desensitization of explosives have increased at home and abroad in recent years. Kim et al. [5], using the supercritical antisolvent (SAS) recrystallization process, prepared micron-sized HMX of different particle sizes with three solvents, dimethylsulfoxide (DMSO), N,N-dimethylformamide (DMF), cyclohexanone, acetone, and N-methyl pyrrolidone (NMP). However, it was obvious from the SEM in the literature that the obtained HMX owned irregular morphology, uneven particle size distribution, and severe agglomeration. Shang et al. [6] fabricated smooth and spherical submicron CL-20 particles by supercritical fluid-enhanced solution diffusion technology with ethyl acetate as the solvent. Although the impact sensitivity was reduced, the crystal structure of the prepared submicron CL-20 particles was $\beta$-CL-20, and the particle agglomeration was also serious. With RESS technology, Matsunaga et al. [7] dissolved $\mathrm{RDX}$ in liquid $\mathrm{CO}_{2}$ under the optimal process conditions and used a reduced solution vapor pressure to rapidly expand the supercritical fluid to obtain high-purity RDX particles of around $110 \mathrm{~nm}$. However, it was clearly seen that RDX particles had serious agglomeration. Wang et al. [8] prepared smooth CL-20 particles with a particle size of $270 \mathrm{~nm}$ using ultrasonic spray-assisted electrostatic adsorption (USEA) technology, and the resultant submicron CL-20 had faster energy release efficiency and more energy release than the conventionally manufactured CL-20. By analysis, the soft agglomeration of submicron CL-20 prepared under optimal conditions was weakened, but the morphology of the particles was irregular. Due to their peculiar activity and van der Waals force and Coulomb force between particles, it was easy to produce soft agglomeration, so their excellent performances could not be fully exerted [9]. Therefore, how to efficiently suppress and eliminate the agglomeration of superfine nitramine explosives has become an important issue for researchers. Many scholars have tried to settle the problem of soft agglomeration of submicron-energetic materials through various alternative methods, such as adding surfactants [10], ultrasound [11], and supercritical fluid drying [12]. However, a few works have been done to effectively solve the soft agglomeration of submicron explosives.

Self-assembly is the process of spontaneously forming a certain shape and structure using noncovalent bonds. These interactions can be phase separation, ionic interaction, hydrogen bonding, and the like. The molecular structures of RDX, HMX, CL-20, and PVA are shown in Figure 1. We consider there is an intermolecular hydrogen bond interaction between the hydroxyl group in the PVA molecule and the negatively charged oxygen in the three explosive molecules. The two molecules can form a self-assembled structure by hydrogen bonding interaction during recrystallization, and such a structure facilitates the formation of relatively regular aggregations during recrystallization. The whole process is realized in the spray drying process, so we call it "a novel spray drying assisted self-assembly (SDAS) technology”.

In our paper, spherical submicron RDX, HMX, and CL-20 particles without soft agglomeration were fabricated via SDAS technology. As a facile and practical explosive refining technology, it can realize large-scale production and effectively solves the problem of severe soft agglomeration caused by van der Waals force and coulomb force between ultrafine explosives, providing key technical support for the superfine explosives to fully exert their excellent performances. Compared to explosives refined by traditional 


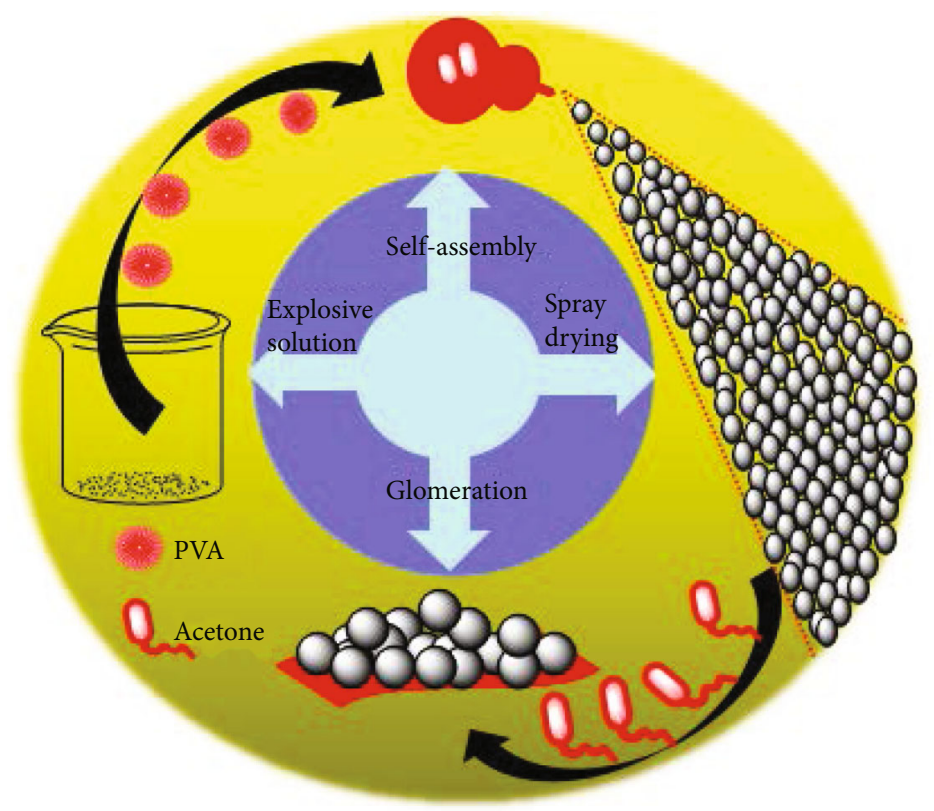

Figure 2: Schematic diagram of SDAS process.

spray recrystallization, in addition to the advantages of no soft agglomeration, the three submicron nitramine explosives prepared by SDAS technology had a stable crystal structure, better thermal decomposition performance, lower impact sensitivity, and friction sensitivity.

\section{Experiment Parts}

2.1. Materials. HMX, RDX, and CL-20 were provided by Gansu Yinguang Chemical Industry Group Co. Acetone was purchased from Tianjin Sailboat Chemical Reagent Technology Co., Ltd. Polyvinyl alcohol 2488 (PVA) was provided by Qingdao Yousuo Chemical Technology Co., Ltd. Pure water was supplied by Taiyuan Iron and Steel Co., Ltd.

\subsection{Spray Drying-Assisted Self-Assembly Technology to Refine} $R D X, H M X$, and CL-20. The steps for preparing submicron scale spherical nitramine explosives using SDAS technology are as follows (this report takes the preparation of submicron scale RDX as an example): First, the RDX was dissolved in acetone to form an RDX solution. Second, a trace amount of $3 \%$ PVA solution was added dropwise to the RDX solution to form an RDX anhydrous microemulsion under ultrasonication. During this process, the volatilization of acetone leads to concentration of PVA and RDX solutions, which induces synergistic self-assembly of RDX and PVA. Next, the RDX anhydrous microemulsion was sprayed through a spray dryer into a drying chamber at a temperature of $80^{\circ} \mathrm{C}$ and collected by a filter. PVA played an important role in the process of acetone being discharged out of the drying chamber. For one thing, it could effectively limit the growth of the crystal planes of each crystal of RDX, and for another, it could actively prevent agglomeration in the RDX nucleation process. The schematic diagram of the SDAS process is shown in Figure 2.
2.3. Spray Recrystallization to Refine RDX, HMX, and CL-20. The traditional spray recrystallization steps to refine RDX, HMX, and CL-20 are as follows (this report takes the refinement of RDX as an example): First, the raw RDX was dissolved in acetone, and the mixture was stirred until completely dissolved. Then, the PVA solution with a trace concentration of $3 \%$ was added dropwise to the RDX solution. Driven by the high-speed compressed gas of the oil-free air compressor, the mixed solution was sprayed into a closed beaker containing a nonsolvent at a certain rotational speed through a self-made nozzle. The explosive solution was atomized into small droplets in the nonsolvent. RDX was crystallized with the recrystallization principle, followed by filtration, freezing, and drying, finally affording refined RDX.

In order to facilitate the comparison of the explosive particles refined by the two methods, the samples prepared by the SDAS technology and spray recrystallization were labeled as sample-1 and sample-2, respectively.

2.4. Characterization. Field-emission scanning electron microscopy (FESEM) images were taken on a MIRA3 LMH SEM (Tescan) at $10 \mathrm{k}$. X-ray diffraction (XRD) patterns were obtained using a DX-2700 X-ray diffractometer (Dandong Haoyuan Corporation, Liaoning, China) with $\mathrm{Cu}-\mathrm{K} \alpha(40 \mathrm{kV}, 30 \mathrm{~mA})$ radiation at $\lambda=1.5418 \AA$. All samples were scanned from $5^{\circ}$ to $50^{\circ}$ with steps 0.03 and $6 \mathrm{~s}$ counting time. Thermal analysis was performed on a differential scanning calorimeter (DSC-131, France Setaram Corporation, Shanghai, China) at heating rates of $10^{\circ} \mathrm{C} / \mathrm{min}$. The impact sensitivity was tested with a homebuilt type 12 drophammer apparatus. The special height $\left(H_{50}\right)$ represents the height from which $2.500 \pm 0.002 \mathrm{~kg}$ drop-hammer will result in an explosive event in $50 \%$ of the trials. In each determination, 25 drop hammer tests were made to calculate the $H_{50}$. 

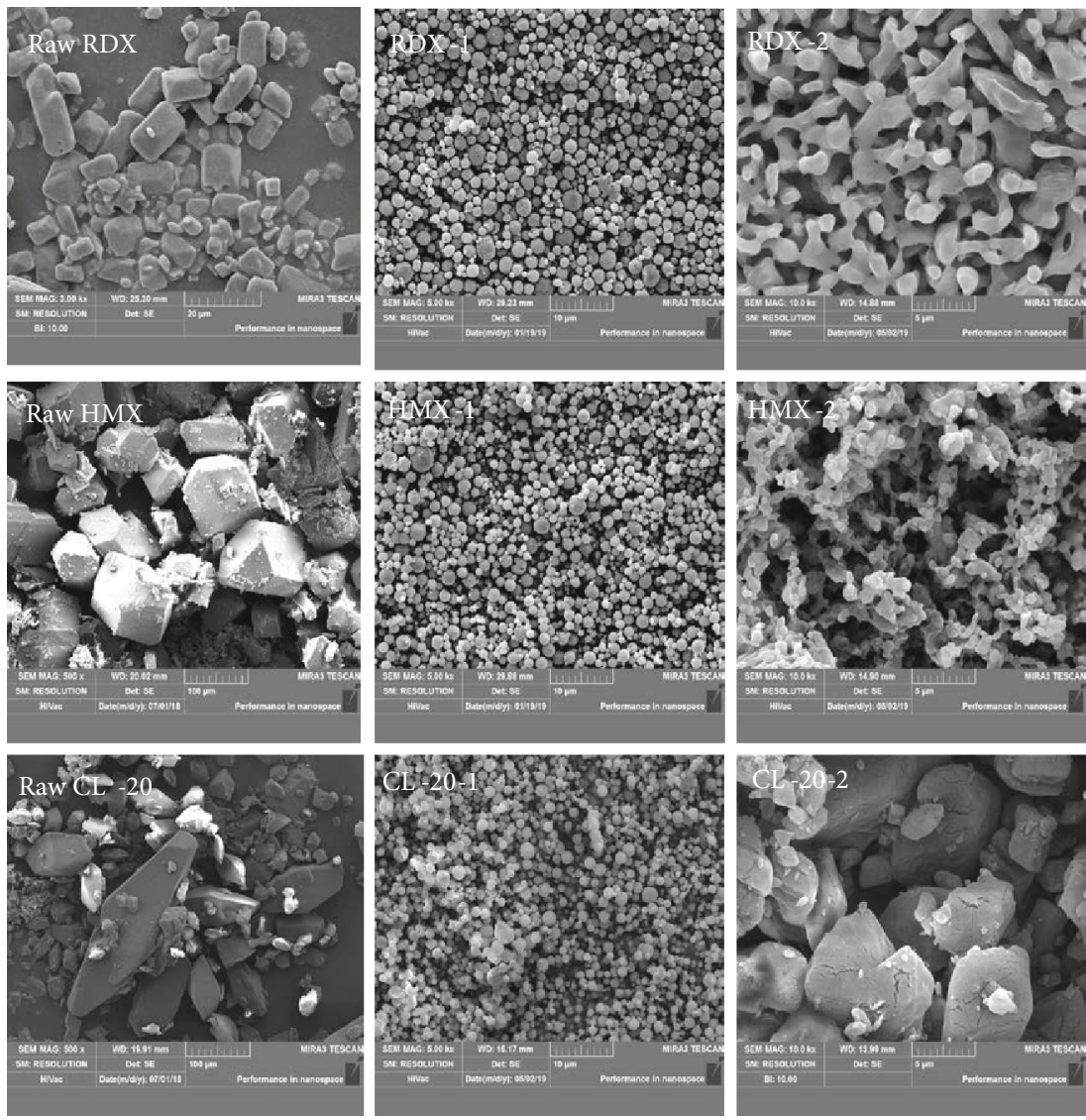

FIGURE 3: SEM image of different samples.

The particle size was tested by a QICPIC dynamic particle analyzer (SYMPATEC Co., Ltd., Germany), and its working environment is $5 \sim 35^{\circ} \mathrm{C}$, relative humidity is less than $85 \%$, light source type is He-Ne laser, power is $2.0 \mathrm{~mW}$, and wavelength is $0.6328 \mu \mathrm{m}$.

\section{Results and Discussion}

3.1. Morphology of the Samples. The morphology and particle size distribution of the three explosive particles refined through the above two methods were measured by SEM and laser particle size analyzer, respectively. The measurement results are illustrated in Figure 3.

The three raw nitramine explosives have irregular morphology and wide particle size distribution, and there are cracks on the surface of the crystal. Interestingly, the raw CL-20 exhibits an irregular spindle shape with sharp edges and corners. The raw HMX shows an irregular square structure with many surface defects. The raw RDX is an orthorhombic crystal with depressions on the crystal surface (as shown in Figure 3). As is well known, the agglomeration of nitramine explosives is a phenomenon of large particle clusters in which multiple ultrafine particles are connected and integrated during recrystallization. The force of this cluster relies mainly on van der Waals forces and Coulomb forces between the ultrafine particles. Therefore, the agglomeration among RDX, HMX, and CL-20 is classified as "soft agglom- eration" according to the cause of agglomeration. For the ordinary recrystallization process, the growth of crystals in explosive solution is a slow growth under approximately equilibrium conditions. As the atoms accumulate on the surface of the growing crystal, they also undergo diffusion and recombination processes on the surface of the crystal. In effect, the "molding process" of crystals mainly includes two processes of crystal nucleation and crystal growth. The crystal nucleation refers to the process in which the explosive solution changes from a metastable state to a stable phase under the action of phase transition driving force. Subsequently, the crystal nucleus undergoes a process of production-diffusion-adsorption-bonding and the like until it finally grows into the shape.

It can be seen from Figure 3 that sample- 1 exhibits uniformly dispersed spherical structures, and almost no particle agglomeration is observed. While sample-2 is irregular in shape, and almost all particles are adhered to each other and agglomerate together. This phenomenon may be related to the "recrystallization nucleation rate" and "the force on the crystal face during the molding process.". The SDAS process is "assembly and molding" by "instantaneous nucleation." Molding in a very short time is not conducive to the attraction and accumulation of the crystal nucleus of the explosive under the action of attraction. Therefore, the obtained particles are uniformly dispersed spheres (sample-1 in Figure 3). The nucleation rate of crystals during spray recrystallization 


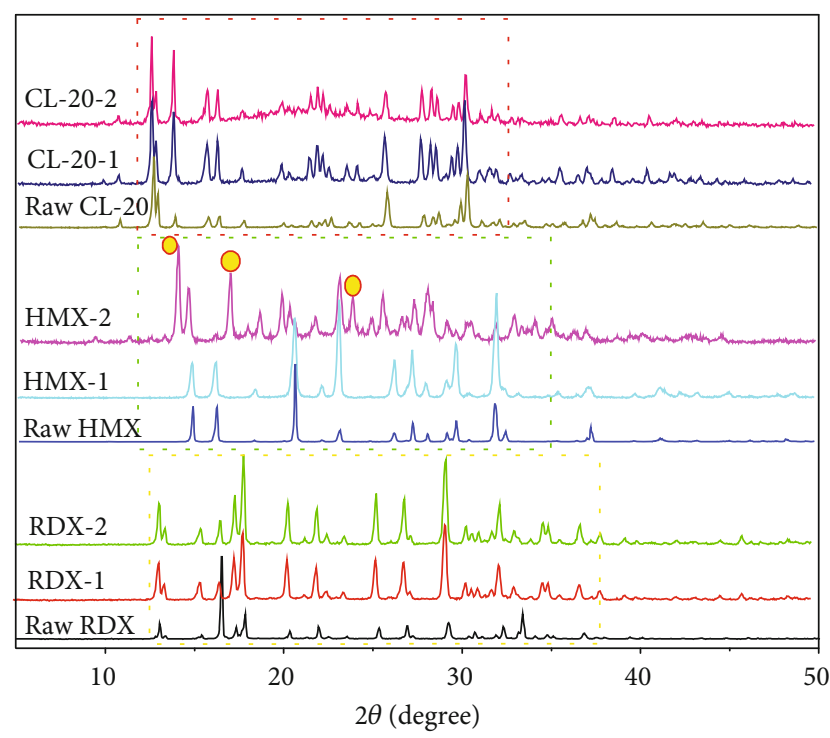

Figure 4: XRD pattern of different samples.

is affected by many external factors such as supersaturation, temperature, and surface free energy. When the explosive concentration reaches the minimum saturation corresponding to the critical free energy, the crystal nucleus begins to grow, and the growth rate increases with the increase of concentration. During this process, a large number of crystal nuclei are deposited and formed until the concentration of the environment required for growth reaches equilibrium. Since the molding time is relatively long, the crystal morphology exhibits an irregular morphology (sample-2 in Figure 3).

3.2. Crystal Structure of Samples. In order to judge the SEM image results more accurately and investigate whether the crystal structure of the refined submicron particles was transformed or destroyed, XRD analysis was carried out. And the test results are displayed in Figure 4.

Figure 4 shows the crystal structures of three different raw nitramine explosives, sample- 1 and sample-2. On the whole, sample- 1 and sample- 2 have almost the same diffraction peaks as the raw nitramine explosives. It is just that the intensity of the diffraction peak changes and the phenomenon that the diffraction peak is broadened is ubiquitous. On the one hand, this is associated with the fact that the particle size is inversely proportional to the peak width of the diffraction peak [13]. On the other hand, it is related to the size of the angle coherent domain between the diffraction first minimum and the maximum [14]. When the particle size of the nitramine explosive is reduced to submicron and the particles cannot be approximated as crystals of the polycrystalline face, the dispersion of the X-rays is aggravated, so that the diffraction peak width is broadened. In the XRD pattern of HMX particles in Figure 4, we find some more interesting phenomena; particularly, the X-ray diffraction peak of the HMX-2 sample does not correspond to that of the raw HMX. And the solid circle inserted in Figure 3 illustrates the presence of some representative new diffraction peaks.
Compared with the PDF card, the XRD pattern of HMX-2 is consistent with that of PDF Card 00-025-1748, but significantly different from that of the raw HMX and HMX-1 (PDF Card 00-044-1620), indicating that the crystal structure of HMX is converted from $\beta$-HMX to $\alpha$-HMX. This is obviously relative to the molding process of the two preparation methods. For SDAS technology, due to the instantaneous precipitation nucleation, the stable $\beta$-HMX has no time to change the crystal structure during the reassembly process. However, the nucleation rate of crystals during spray recrystallization is relatively slow, and multiple external environmental factors like temperature and supersaturation during the molding process become the inducing factors leading to the transformation of the HMX crystal structure.

3.3. Thermal Properties. Probing the thermal decomposition process was very important for energetic materials [15-17]. In our research, DSC cures collected at a heating rate of $10^{\circ} \mathrm{C} / \mathrm{min}$ are obtained in Figure 5. We have found some interesting phenomena about thermal decomposition of the three nitramine explosives. Overall, HMX and CL-20 had similar thermal decomposition characteristics, and there was an endothermic peak of crystal transformation during thermal decomposition. This is attributed to the fact that the decomposition of the explosive molecules does not immediately form the final decomposition product. When the temperature is relatively low, the number of activated molecules is small, and the explosive molecules are in a relatively stable state. As the temperature rises, the number of activated molecules increases, and the decomposition rate increases until the decomposition stops. However, the selfheating phenomenon of CL-20 is more serious than that of HMX (Figure 5), which is probably related to the difference in the crystal structure between the two. That is, CL-20 is a cage-shaped nitramine explosive; the cleavage of the molecular skeleton, decomposition gas products, and the "heterogeneous condensed phase reaction" of the condensed phase exist simultaneously and exacerbate, while HMX is a type of "decomposition-melting" material; and its melting process is affected by the thermal decomposition process. In fact, HMX and RDX also have similar thermal behavior because HMX has the same branched chains as RDX. The difference is that HMX decomposes and releases heat rapidly, and its DSC curve exhibits a sharp spike.

What is interesting is that compared with the raw materials, the thermal decomposition peak temperatures of the three refined nitramine explosives were all advanced with different levels. The thermal decomposition peak temperatures of RDX-1, RDX-2, HMX-1, HMX-2, CL-20-1, and CL-20-2 were decreased by $1.51^{\circ} \mathrm{C}, 4.47^{\circ} \mathrm{C}, 2.13^{\circ} \mathrm{C}, 13.49^{\circ} \mathrm{C}, 2.55^{\circ} \mathrm{C}$, and $8.2^{\circ} \mathrm{C}$, respectively. This is because the refined explosive has a decreased particle size and an increased specific surface area. At a certain heating rate, the energy absorbed from the outside over a period of time increases, and the activity of the explosive particles accordingly increases, thereby lowering the maximum decomposition peak temperature. Surprisingly, the thermal decomposition peak temperature of sample-2 was significantly earlier than that of sample-1, which should relate to the large agglomeration of particles 

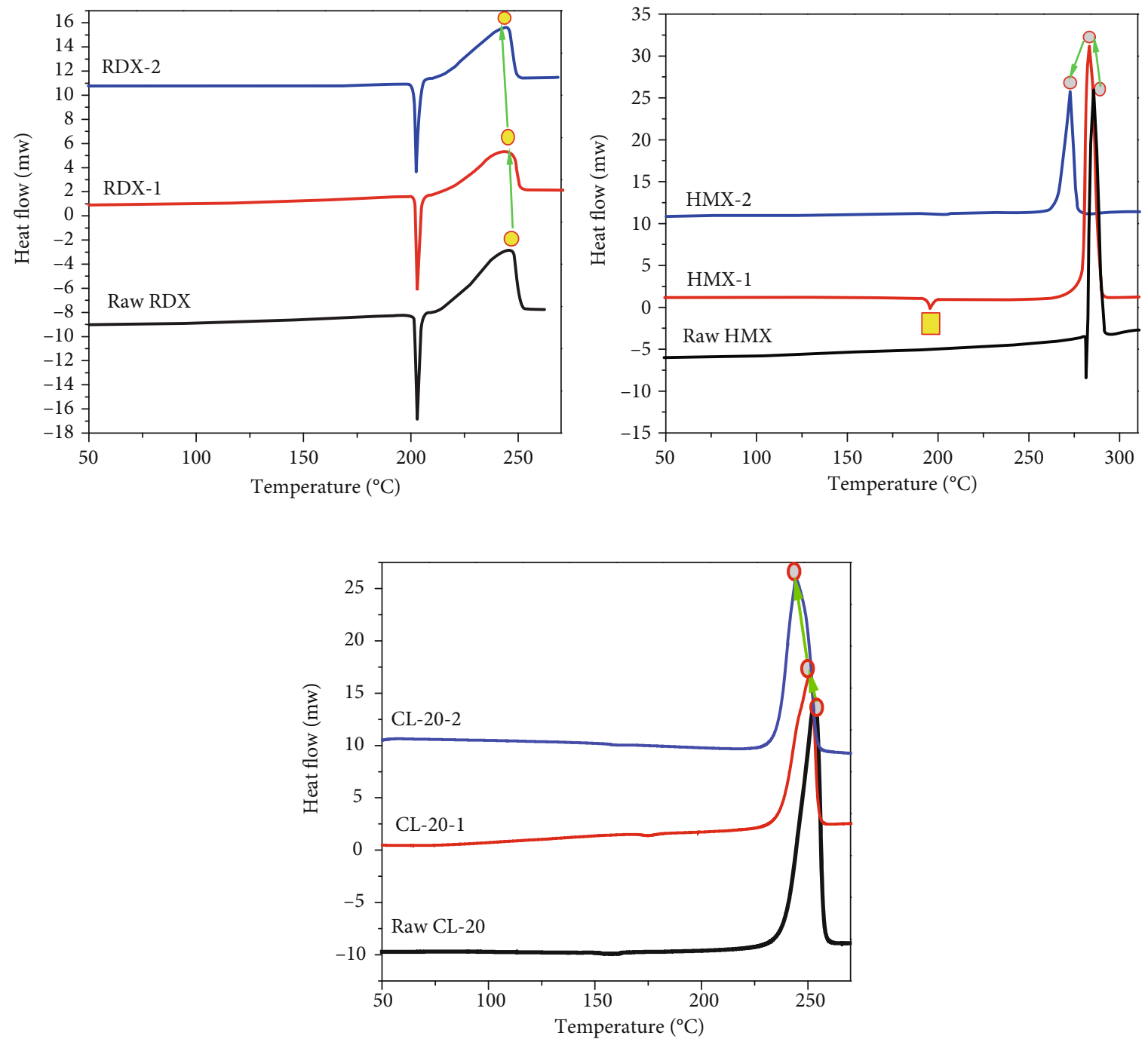

Figure 5: DSC chart of different samples.

[18]. In general, compared to the explosive refined via recrystallization (sample-2), the thermal decomposition peak temperature of the particles prepared by SDAS technology (sample-1) was relatively inconspicuous in advance, and the thermal stability was relatively better.

3.4. Safety Performance. Impact sensitivity and friction sensitivity are also the key parameters to evaluate the safety performance of energetic materials [19-21]. In our paper, the impact sensitivity and friction sensitivity of the raw elemental explosive and the samples before and after refinement were tested. And the results are presented in Table 1. As can be seen from Table 1, after refinement, the impact sensitivity and friction sensitivity of the samples were greatly reduced, thus obviously improving the safety performance. In particular, the $H_{50}$ of RDX, HMX, and CL-20 particles after SDAS technology were increased from $25.6 \mathrm{~cm}, 22.3 \mathrm{~cm}$, and $13.2 \mathrm{~cm}$ to $48.3 \mathrm{~cm}, 44.6 \mathrm{~cm}$, and $31.1 \mathrm{~cm}$, respectively. And the probability of explosion probability $(P, \%)$ was reduced from $92 \%, 94 \%, 100 \%$ to $62 \%, 62 \%$, and $80 \%$, respectively.
TABLE 1: Impact sensitivity and friction sensitivity of samples.

\begin{tabular}{lcc}
\hline Samples & $H_{50}(\mathrm{~cm})$ & $P(\%)$ \\
\hline Raw RDX & 25.6 & 92 \\
RDX-1 & 48.3 & 62 \\
RDX-2 & 33.4 & 74 \\
Raw HMX & 22.3 & 92 \\
HMX-1 & 44.6 & 62 \\
HMX-2 & 32.7 & 76 \\
Raw CL-20 & 13.2 & 100 \\
CL-20-1 & 31.1 & 80 \\
CL-20-2 & 22.6 & 92 \\
\hline
\end{tabular}

This is attributed to the fact that the appearance of the refined elemental explosive tends to be smooth, and the internal defects are gradually reduced, so that the heat transfer rate between the particles is increased, and it is difficult to 
form a hot spot when subjected to an external force. Furthermore, in comparison with the sample- 2 refined by the spray recrystallization method, the particle size distribution of the particle (sample-1) prepared by SDAS technology was more uniform and the spheroidization effect was more evident. Meanwhile, the dispersed surface area and the gap between the particles were larger, and the pressure from the falling ball at the same height was smaller. Hence, the safety performance performed superior.

\section{Conclusions}

In this paper, three submicron RDX, HMX, and CL-20 particles with uniform particle size distribution were prepared by spray drying-assisted self-assembly (SDAS) technology. The XRD analysis proved that HMX and CL-20 fabricated by SDAS technology maintained the crystal structure of $\beta$-HMX and $\varepsilon$-CL-20 before and after the refinement process, whereas the HMX crystal structure after spray recrystallization refinement was transformed from $\beta$-HMX to $\alpha$-HMX. It was found that compared with the sample refined by spray recrystallization, the three samples refined by the SDAS possessed better thermal stability and lower impact sensitivity and friction sensitivity. SDAS technology is a facile and practical explosive refining technology and has the advantage of easy realization of large-scale production. It can effectively resolve the serious soft agglomeration issue caused by van der Waals force and Coulomb force between ultrafine explosives, providing key technical support for the ultrafine explosives to fully exert their excellent performances.

\section{Data Availability}

The data used to support the findings of this study are available from the corresponding authors upon request.

\section{Conflicts of Interest}

The authors declare that they have no conflicts of interest.

\section{References}

[1] B. Bhushan, A. Halasz, S. Thiboutot, G. Ampleman, and J. Hawari, "Chemotaxis-mediated biodegradation of cyclic nitramine explosives RDX, HMX, and CL-20 by Clostridium sp. EDB2," Biochemical and Biophysical Research Communications, vol. 316, no. 3, pp. 816-821, 2004.

[2] R. S. Damse, A. Singh, and H. Singh, "High energy propellants for advanced gun ammunition based on RDX, GAP and TAGN compositions," Propellants, Explosives, Pyrotechnics, vol. 32, no. 1, pp. 52-60, 2010.

[3] Y. F. Ivanov, M. N. Osmonoliev, V. S. Sedoi et al., "Productions of ultra-fine powders and their use in high energetic compositions," Propellants, Explosives, Pyrotechnics, vol. 28, no. 6, pp. 319-333, 2010.

[4] A. E. D. M. van der Heijden and R. H. B. Bouma, "Crystallization and characterization of RDX, HMX, and CL-20," Crystal Growth \& Design, vol. 4, no. 5, pp. 999-1007, 2004.

[5] C. K. Kim, B. C. Lee, Y. W. Lee, and H. S. Kim, "Solvent effect on particle morphology in recrystallization of HMX (cyclote- tramethylenetetranitramine) using supercritical carbon dioxide as antisolvent," Korean Journal of Chemical Engineering, vol. 26, no. 4, pp. 1125-1129, 2009.

[6] F.-F. Shang, J.-L. Zhang, X.-L. Zhang, and J.-Y. Wang, "Preparation and characterization of nano-CL-20 with solution enhanced dispersion by supercritical fluids," Chinese Journal of Explosives \& Propellants, vol. 35, no. 6, pp. 37-40, 2012.

[7] T. Matsunaga, A. V. Chernyshev, E. N. Chesnokov, and L. N. Krasnoperov, "In situ optical monitoring of RDX nanoparticles formation during rapid expansion of supercritical $\mathrm{CO}_{2}$ solutions," Physical Chemistry Chemical Physics, vol. 9, no. 38, pp. 5249-5259, 2007.

[8] D. Wang, B. Gao, G. Yang, F. Nie, and H. Huang, "Preparation of CL-20 explosive nanoparticles and their thermal decomposition property," Journal of Nanomaterials, vol. 2016, Article ID 5462097, 7 pages, 2016.

[9] K. J. Kim and H. S. Kim, "Agglomeration of NTO on the surface of HMX particles in water-NMP solvent," Crystal Research and Technology, vol. 43, no. 1, pp. 87-92, 2008.

[10] J. Wang, S. Thongngamdee, and A. Kumar, "Highly stable voltammetric detection of nitroaromatic explosives in the presence of organic surfactants at a polyphenol-coated carbon electrode," Electroanalysis, vol. 16, no. 15, pp. 1232-1235, 2004.

[11] E. V. Kuz'min, A. P. Peev, S. V. Kuz'min, and V. I. Lysak, "Structure formation and properties of a copper-aluminum joint produced by ultrasound-assisted explosive welding," Physics of Metals and Metallography, vol. 118, no. 8, pp. 820826, 2017.

[12] W. H. Griest, C. Guzman, and M. Dekker, "Packed-column supercritical fluid chromatographic separation of highly explosive compounds," Journal of Chromatography A, vol. 467, no. 2, pp. 423-429, 1989.

[13] J. M. Lebrun, S. K. Jha, K. S. Naik, K. C. Seymour, W. M. Kriven, and R. Raj, "The change of X-ray diffraction peak width During in situ Conventional sintering of nanoscale powders," Journal of the American Ceramic Society, vol. 99, no. 3, pp. 765-768, 2015.

[14] J. Wang, B. Ye, C. An, B. Wu, H. Li, and Y. Wei, "Preparation and properties of surface-coated HMX with viton and graphene oxide," Journal of Energetic Materials, vol. 34, no. 3, pp. 235-245, 2016.

[15] C. An, H. Li, B. Ye, and J. Wang, "Nano-CL-20/HMX cocrystal explosive for significantly reduced mechanical sensitivity," Journal of Nanomaterials, vol. 2017, Article ID 3791320, 7 pages, 2017.

[16] X. Jia, J. Wang, C. Hou, and Y. Tan, "Green preparation, spheroidal, and superior property of nano-1,3,5,7-tetranittro1,3,5,7-tetrazocane," Journal of Nanomaterials, vol. 2018, Article ID 5839037, 8 pages, 2018.

[17] J. Wang, J. Li, C. An, C. Hou, W. Xu, and X. Li, "Study on ultrasound- and spray-assisted precipitation of CL-20," Propellants Explosives Pyrotechnics, vol. 37, no. 6, pp. 670-675, 2012.

[18] X. Jia, J. Wang, C. Hou, Y. Tan, and Y. Zhang, "Effective insensitiveness of melamine urea-formaldehyde resin via interfacial polymerization on nitramine explosives," Nanoscale Research Letters, vol. 13, no. 1, p. 402, 2018.

[19] X. Jia, C. Hou, Y. Tan, J. Wang, and B. Ye, "Fabrication and characterization of PMMA/HMX-based microcapsules via in situ polymerization," Central European Journal of Energetic Materials, vol. 14, no. 3, pp. 559-572, 2017. 
[20] Y. Bayat and V. Zeynali, "Preparation and characterization of nano-CL-20 Explosive," Journal of Energetic Materials, vol. 29, no. 4, pp. 281-291, 2011.

[21] B. Y. Ye, C. W. An, J. Y. Wang, and X. H. Geng, "Formation and properties of HMX-based microspHeres via spray drying," RSC Advances, vol. 7, no. 56, pp. 35411-35416, 2017. 


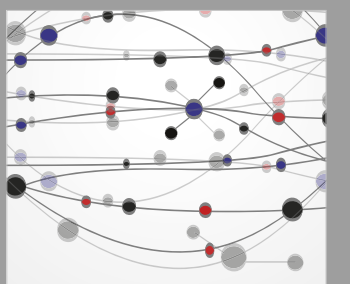

The Scientific World Journal
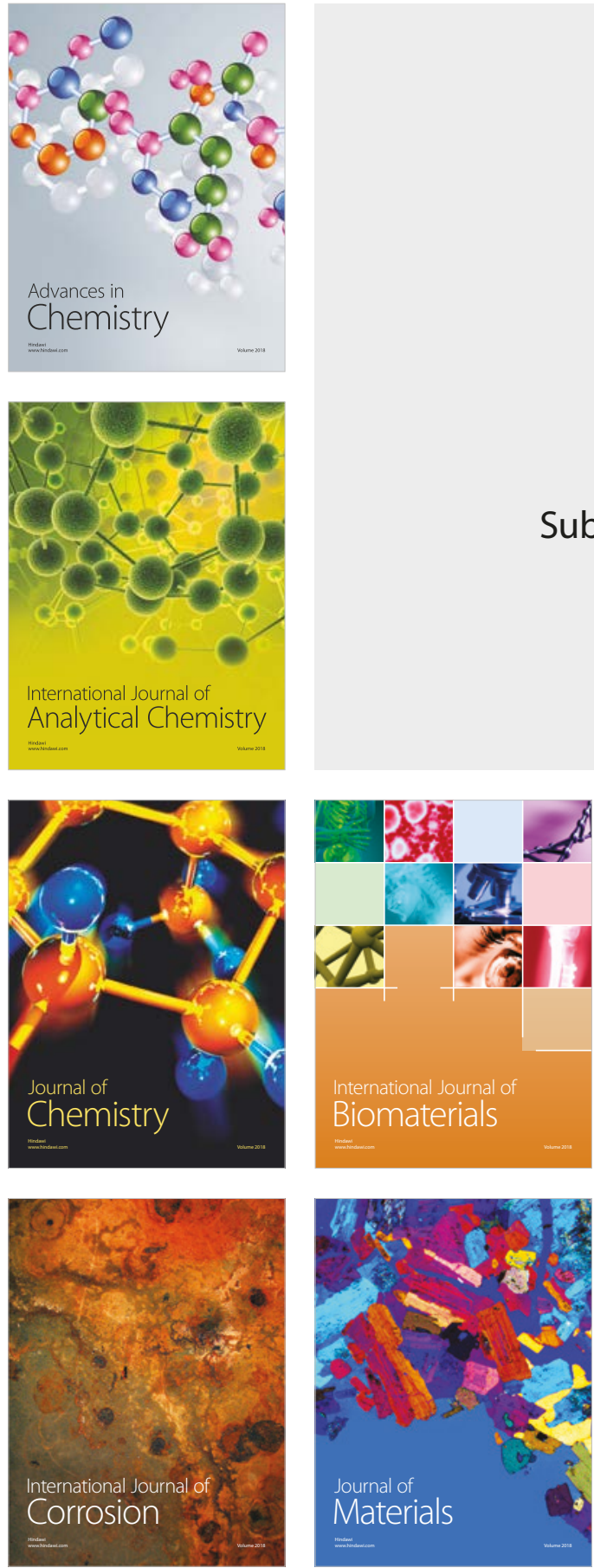

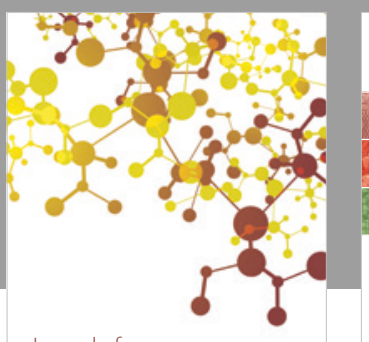

Journal of

Applied Chemistry
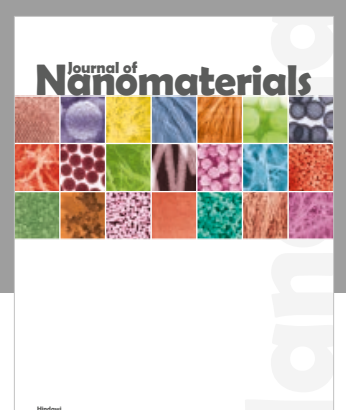

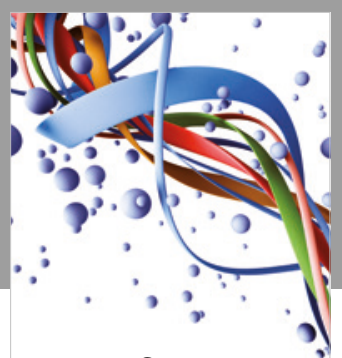

Scientifica

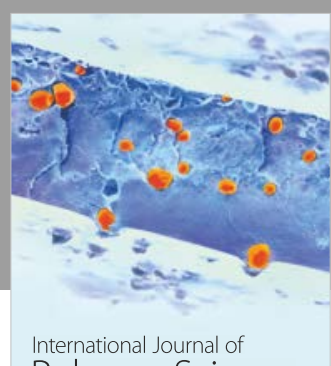

Polymer Science

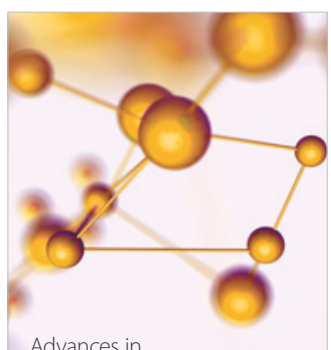

Physical Chemistry
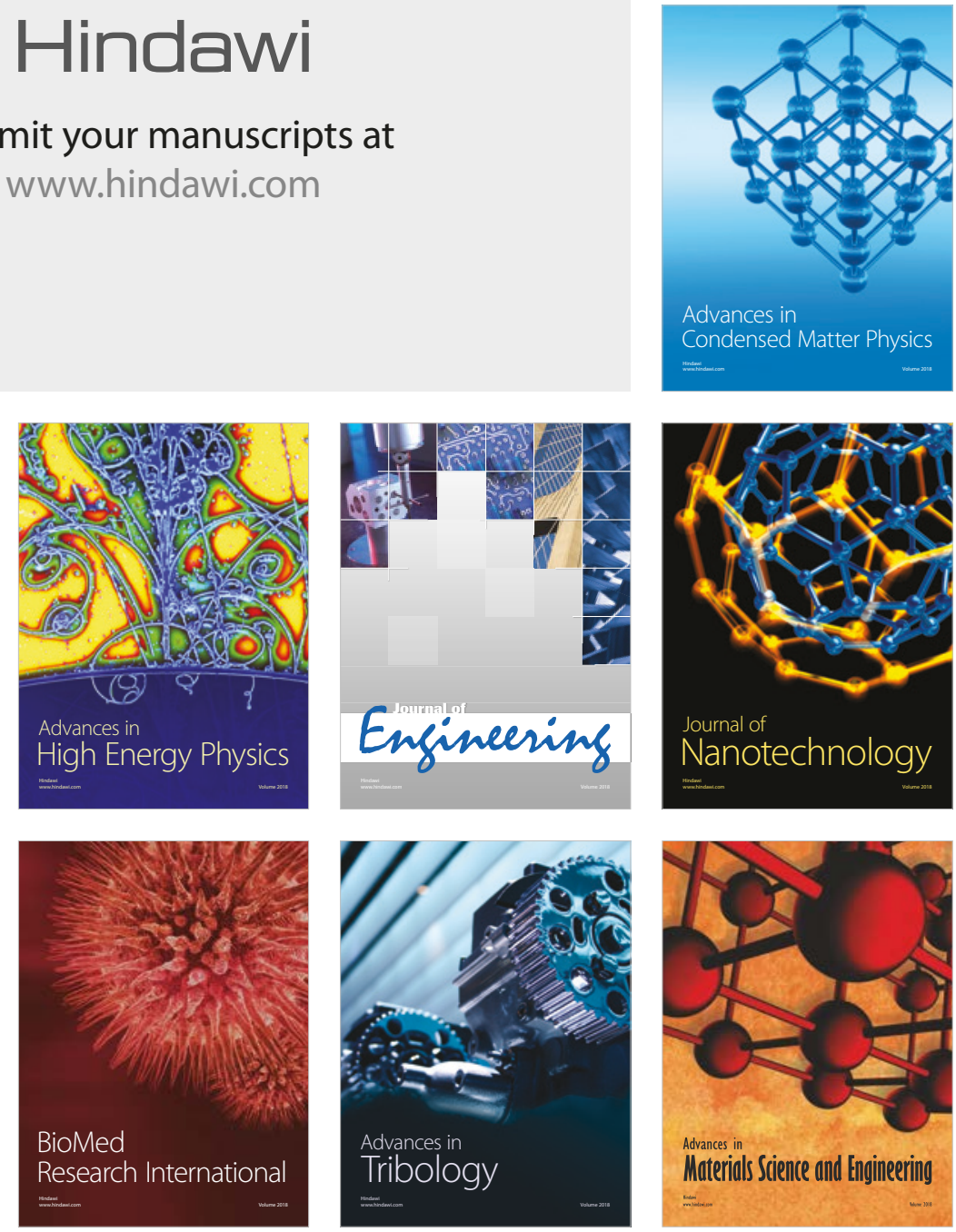